\title{
Adding colchicine to immunosuppressive treatments; a potential option for biologics-refractory adult-onset Still's disease
}

Tomoyuki Asano, Makiko Yashiro Furuya, Shuzo Sato, Hiroko Kobayashi, Hiroshi Watanabe, Eiji Suzuki and Kiyoshi Migita*

\begin{abstract}
Background: Adult-onset Still's disease (AOSD) is a rare inflammatory disorder characterized by the classical triad of daily spiking fever, arthritis, and typical salmon-colored rash. Resistance to first-line corticosteroids and second-line disease modified anti-rheumatic-drugs defines refractory AOSD, which mostly includes the polycyclic or chronic courses of the disease. Anti-cytokine therapies are recommended in AOSD patients who are refractory to traditional treatments. This is the first report on the efficacy of colchicine in a patient with AOSD which was refractory to immunosuppressive treatments including biologics.

Case presentation: A 24-years Japanese female patient was referred to our hospital for the flare-up of AOSD under the combined treatments with steroid, immunosuppressants, and biologics. She was diagnosed with AOSD according to the Yamaguchi criteria, based on the presence of spiking fever, polyarthralgia, skin rash, and hyperferritinemia. Interleukin-6 or tumor necrosis factor-a blockade treatments were not effective, the oral administration of colchicine was stared under the immunosuppressive treatments with steroid and cyclosporine A (CyA). Colchicine treatment silenced the disease activity of AOSD. The dose of prednisolone was successfully tapered, and the elevated levels of C-reactive protein were normalized. Remission has been maintained for 13 months with the start of oral administration of colchicine.
\end{abstract}

Conclusion: We concluded that colchicine is an alternative treatment in patients with refractory AOSD, particularly in those with impaired therapeutic effects against anti-cytokines therapies.

Keywords: Adult-onset Still's disease, Colchicine, Cyclosporin A, Tocilizumab

\section{Background}

Adult onset Still's disease (AOSD) is a rare chronic inflammatory disorder that usually accompanied with high spiking fever, arthritis and salmon pink skin rash [1]. The wide range of disease manifestations and course suggest heterogeneity of the disease entity [2]. Macrophage activation and subsequent overproduction of cytokines are involved in the pathogenesis of AOSD [3]. Therefore,

\footnotetext{
*Correspondence: migita@fmu.ac.jp

Department of Rheumatology, Fukushima Medical University School
}

of Medicine, 1 Hikarigaoka Fukushima, Fukushima 960-1295, Japan cytokine-directed therapies have the potential to target macrophage-activation seen in AOSD [4]. Also, recent insights into autoinflammatory disorders have indicated that interleukin (IL)-1 blockers may be effective against steroid-refractory or immunosuppressant-refractory AOSD [5]. To treat steroid-resistant AOSD, previous reports have suggested the use of immunosuppressants such as methotrexate and cyclosporine A [6]. Additionally, anti-cytokine treatments including TNF or IL-6 blockers appear to be an efficient well-tolerated, steroidsparing treatment against immunosuppressants-refractory AOSD [7]. The application of these biologics may 
provide clinicians with useful tools for the management of refractory AOSD. While targeting these cytokines has shown promising effects [7], there remain AOSD patients who do not respond to these biologics [8] and they are associated with potential severe side effects. This is the first report on the successful induction of remission with colchicine in biologics-refractory AOSD.

\section{Case presentation}

24-year-old female patient was referred to our hospital because of spiking fever, arthritis in the proximal interphalangeal joints, wrists, and knees. She had been diagnosed with a systemic type of AOSD. The onset occurred 9 months previously, with acute attack of fever, bilateral tenderness and swelling over both wrists and knee joints, sore throat, and hyperferritinemia $(17,900 \mathrm{ng} /$ $\mathrm{mL}$ ). The patient was diagnosed with AOSD according to the criteria of Yamaguchi et al. [9], and started on prednisolone $(60 \mathrm{mg} /$ day $)$ and methotrexate $(10 \mathrm{mg} /$ week). However, the spiking fever was sustained, and thus tacrolimus $(3 \mathrm{mg} /$ day $)$ and tocilizumab $(8 \mathrm{mg} / \mathrm{kg}$, every 4 weeks) were combined with these treatments. During that time, the patient reported some improvement. However, despite this treatment, her arthralgia increased and elevated C-reactive (CRP) was observed. Tocilizumab $(8 \mathrm{mg} / \mathrm{kg})$ was switched to infliximab (3 $\mathrm{mg} / \mathrm{kg})$, however, elevated serum levels of ferritin and CRP were sustained (Fig. 1). She had no episodes of persistent fever of unknown origin, and no symptoms such as arthritis, and skin rash that were indicative of autoimmune disease. There was no family history for autoimmune or autoinflammatory diseases.

Upon examination, inflammatory arthritis of the ankle and knee joints coinciding with the erythematous skin rash on her trunk and spiking fever $\left(>39{ }^{\circ} \mathrm{C}\right)$ were evident. Laboratory data on admission were as follows (Table 1): leukocytes, 19,000/ $\mu \mathrm{L}$ (neutrophils, 90.0\%); hemoglobin, $9.6 \mathrm{~g} / \mathrm{dL}$; platelets, $31.7 \times 10^{4} / \mu \mathrm{L}$; erythrocyte sedimentation rate, $41 \mathrm{~mm}(1 \mathrm{~h})$; C-reactive protein, $19.85 \mathrm{mg} / \mathrm{dL}$; soluble interleukin-2 receptor, $1340 \mathrm{IU} / \mathrm{L}$; and ferritin, $1719 \mathrm{ng} / \mathrm{mL}$. Cytomegalovirus (CMV) antigenemia showed negative results. Urinary infection was confirmed and treated with antibiotics. Infliximab and tacrolimus were stopped, and she was treated with

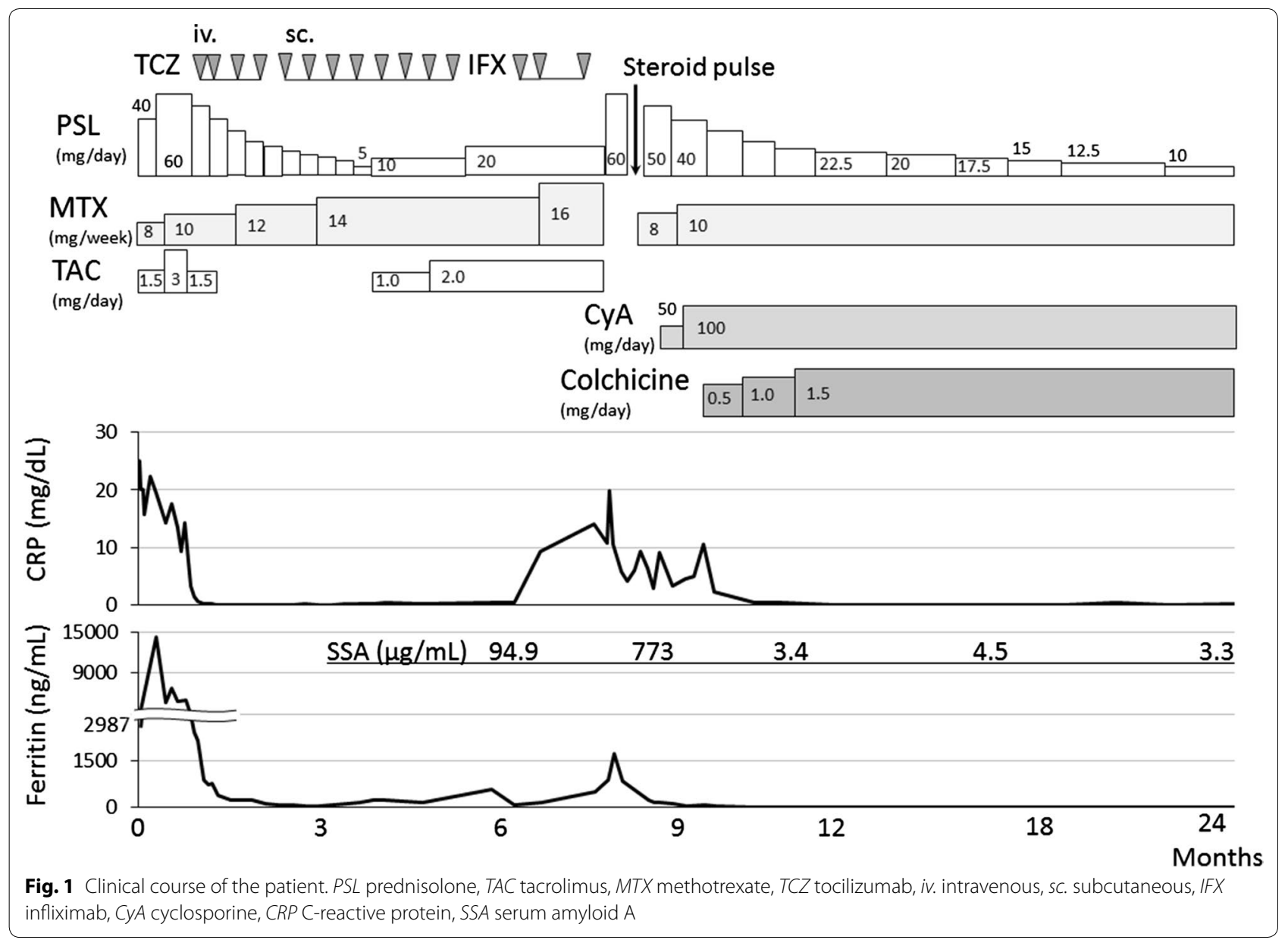


Table 1 Laboratory findings on admission

\begin{tabular}{|c|c|c|c|}
\hline \multicolumn{2}{|l|}{ Peripheral blood } & \multicolumn{2}{|l|}{ Serological tests } \\
\hline White blood cells & $19,000 / \mu \mathrm{L}$ & C-reactive protein & $19.85 \mathrm{mg} / \mathrm{dL}$ \\
\hline Neutriphil & $90.0 \%$ & ESR (1 h) & $41 \mathrm{~mm}$ \\
\hline Lymphocyte & $4.0 \%$ & sIL-2R & $1340 \mathrm{U} / \mathrm{mL}$ \\
\hline Monocyte & $4.0 \%$ & $\lg G$ & $1752 \mathrm{mg} / \mathrm{dL}$ \\
\hline Eosinophil & $1.0 \%$ & $\lg A$ & 235 mg/dL \\
\hline Basophil & $1.0 \%$ & $\lg M$ & $374 \mathrm{mg} / \mathrm{dL}$ \\
\hline Red blood cells & $4.61 \times 10^{6} / \mu \mathrm{L}$ & $\mathrm{C} 3$ & 95 mg/dL \\
\hline Hemoglobin & $9.6 \mathrm{~g} / \mathrm{dL}$ & C4 & $16 \mathrm{mg} / \mathrm{dL}$ \\
\hline Hematocrit & $32.4 \%$ & Rheumatoid factor & $8.0 \mathrm{IU} / \mathrm{mL}$ \\
\hline Platelet & $31.7 \times 10^{4} / \mu \mathrm{L}$ & ANA & $<80 \times$ \\
\hline Blood chemistry & & Anti-ds DNA Ab & $0.6 \mathrm{IU} / \mathrm{mL}$ \\
\hline Total protein & $8.2 \mathrm{~g} / \mathrm{dL}$ & Anti-SSA Ab & $<0.5 \mathrm{U} / \mathrm{mL}$ \\
\hline Albumin & $3.6 \mathrm{~g} / \mathrm{dL}$ & SAA & $773 \mu \mathrm{g} / \mathrm{mL}(<8.0)$ \\
\hline Total bilirubin & $0.6 \mathrm{mg} / \mathrm{dL}$ & MMP-3 & $225 \mathrm{ng} / \mathrm{mL}(17.3-59.7)$ \\
\hline Aspartate transaminase & $48 \mathrm{U} / \mathrm{L}$ & Procalcitonin & $3.89 \mathrm{ng} / \mathrm{mL}(<0.05)$ \\
\hline Alanine transaminase & $11 \mathrm{U} / \mathrm{L}$ & Urinalysis & \\
\hline Lactate dehydrogenase & 797 U/L & Glucose & $(-)$ \\
\hline Alkaline phosphatase & $224 \mathrm{U} / \mathrm{L}$ & Protein & $(1+)$ \\
\hline Y-Glutamyltranspeptidase & $26 \mathrm{U} / \mathrm{L}$ & Neutrophils (sediment) & $(3+)$ \\
\hline Creatine kinase & $27 \mathrm{U} / \mathrm{L}$ & Infection & \\
\hline Blood urea nitrogen & $12 \mathrm{mg} / \mathrm{dL}$ & $\mathrm{HBs} A g$ & $(-)$ \\
\hline Creatinine & $1.23 \mathrm{mg} / \mathrm{dL}$ & HCV Ab & $(-)$ \\
\hline Sodium & $138 \mathrm{mEq} / \mathrm{L}$ & ASLO & $275 \mathrm{IU} / \mathrm{mL}(<240)$ \\
\hline Potassium & $3.8 \mathrm{mEq} / \mathrm{L}$ & Parvovirus B19 lgM & 0.39 index $(<0.79)$ \\
\hline Chlorine & 99 mEq/L & CMV antigenemia & $(-)$ \\
\hline Ferritin & $1719 \mathrm{ng} / \mathrm{mL}$ & Blood culture & $(-)$ \\
\hline
\end{tabular}

ESR erythrocyte sedimentation rate, slL-2R soluble interleukin-2 receptor, I $g$ immunoglobulin, ANA anti-nuclearantibody, Anti-ds-DNA Ab anti-double stranded deoxyribonucleic acid antibody, $S A A$ serum amyloid $\mathrm{A}, M M P-3$ matrix metalloproteinase-3, $H B s$ Ag hepatitis $\mathrm{B}$ virus surface antigen, $H C V A b$ anti-hepatitis $C$ virus antibody, ASLO anti-streptolysin O, CMV cytomegalovirus

prednisolone and methotrexate (16 mg/week). However, her AOSD was not remitted, and hyperferritinemia was observed. Therefore, the dose of prednisolone was transiently increased to $60 \mathrm{mg} /$ day and tacrolimus (TAC) was switched to cyclosporin A (CyA, $100 \mathrm{mg} /$ day) because of lack of efficacy. In addition, colchicine $(1.5 \mathrm{mg} /$ day $)$ was added to these treatments. The combined treatments silenced the disease activity of AOSD, and the dose of prednisolone was successfully tapered. Elevated levels of serum amyloid A (SAA; $773 \mu \mathrm{g} / \mathrm{mL})$ and ferritin $(1719 \mathrm{ng} / \mathrm{mL})$ were also normalized. An analysis of the Mediterranean fever (MEFV) gene (exons 1-10) was performed by direct sequencing, but no mutation was detected. Six weeks later, the patient was discharged from the hospital. The administration of colchicine was continued and the dose of PSL was gradually tapered (Fig. 1). The patient's clinical course remained unchanged and AOSD was successfully controlled in remission under the low-dose steroid treatment (PSL $10 \mathrm{mg} /$ day) over the subsequent 15 months of follow-up (Fig. 1).

\section{Discussions and conclusions}

Our patient is the first to be reported for effectiveness of colchicine in AOSD. The patient was treated with colchicine, and showed improvement of their clinical manifestations, such as fever and arthropathy, and normalization of their serum levels of CRP and ferritin. Although the data available to date remain limited because of the rarity of the disease, it seems clear that use of colchicine represents a good alternative to biologics therapies, which can potentially cause adverse events including infections.

The first-line therapy in AOSD is based on corticosteroid, but has various side effects [6]. Thus, immunosuppressants, such as methotrexate and cyclosporin A, have been used [10]. Recent studies demonstrated that tocilizumab treatment resulted in clinical and laboratory improvements in patients with AOSD refractory to treatment with other biologics [11]. However, in the present report, our patient was refractory to IL-6 or tumor necrosis factor (TNF)- $\alpha$ blockade treatments. Whereas the administration of colchicine resulted in 
long-term clinical remission in this case. It should be debated whether steroid pulse therapy may result in the clinical resolution of AOSD in this case. However, the effectiveness of colchicine in preventing febrile attacks was demonstrated even under the minimum dose steroid (PSL $8 \mathrm{mg} /$ day) and one-course of steroid pulse therapy may not result in long-term of clinical remission of AOSD in this patient.

It could be also argued that the switch from TAC to CyA silenced the AOSD manifestations in this case. Mitamura et al., reported that CyA administration improved AOSD [12]. In contrast, Nakamura et al. reported that TAC, a calcineurin inhibitor similar to CyA, could be one of the useful option for refractory AOSD [13]. Murakami et al. reported a patient with AOSD successfully treated with TAC, while CyA was not effective [14]. Although there is no clear evidence that CyA, may be superior to TAC in the effectiveness of AOSD treatments, CyA should be comparable to TAC for treating AOSD.

Autoinflammatory diseases affect the innate immune system, and some of them are characterized by inflammasome activation and subsequent IL-1 $\beta$ production [15]. The clinical manifestations of autoinflammatory diseases are similar to those of AOSD, and a dramatic response to IL-1 $\beta$ blockade was reported in Western countries [16]. Nevertheless, IL-1 $\beta$ blockade treatment is not available for Japanese patients with AOSD. The finding that colchicine was effective in AOSD refractory to TNF- $\alpha$ or IL-6 blockade is interesting. Patients with heterozygous $M E F V$ mutations with low penetrance were reported to present with clinical manifestations resembling familial Mediterranean fever (FMF) [17]. These reports indicate that the $M E F V$ gene is not only associated with a single disease, FMF, but also linked to additional clinical presentations of autoinflammatory diseases [18]. The mutation analysis in our patient demonstrated no abnormalities in the $M E F V$ gene. Therefore, the current case report suggests that colchicine is effective for nonFMF or non- $M E F V$ gene-associated entities, because $M E F V$ mutations typical to FMF were not demonstrated. Colchicine is widely used in rheumatology therapy for gout, FMF, and Bechet's disease [19]. Its mode of action includes chemokines, and inhibition of neutrophils and endothelial cell adhesion molecules [20]. A recent investigation demonstrated that colchicine inhibits the assembly of the inflammasome complex by affecting the transport of apoptosis-associated speck-like protein containing caspase recruitment domain (ASC), an adaptor protein [21]. These findings suggest that colchicine may modulate the inflammasome-mediated proinflammatory cascades and that the broad concept of colchicineresponsive inflammatory conditions can be reconsidered.
Our case report indicated that colchicine may be one of treatment options for refractory AOSD.

This is the first case report in which colchicine has been used to treat AOSD refractory to biologics treatment. Colchicine treatment resulted in clinical remission of refractory AOSD and allowed a large reduction of steroid doses in this case. Colchicine should be considered as one of the therapeutic options for AOSD refractory to anti-cytokines treatment.

\section{Abbreviations \\ AOSD: adult onset Still's disease; CyA: cyclosporin A; DMARDs: disease modi- fied anti-rheumatic-drugs; FMF: familial Mediterranean fever; IL-6: interleukin-6; TAC: tacrolimus; TNF-a: tumor necrosis factor-a. \\ Authors' contributions \\ TA, MYF, SS, HK, HW, ES and HM made substantial contributions to concep- tion and acquisition of data and analysis and interpretation of data. TA and KM helped to draft the manuscript. All authors read and approved the final manuscript.}

\section{Acknowledgements}

Not applicable.

\section{Competing interests}

The authors declare that they have no competing interests.

\section{Availability of data and materials}

The dataset supporting the conclusions of this article was included within the article and its additional file.

\section{Consent to publish}

Written informed consent was obtained from the patient for publication of this case report and any accompanying data.

\section{Ethics approval and consent to participate}

This study was approved by the Ethics Committees Fukushima Medical University (No. 2920) and written informed consent was obtained for genetic analysis.

Funding

There was no research grant for this study.

\section{Publisher's Note}

Springer Nature remains neutral with regard to jurisdictional claims in published maps and institutional affiliations.

Received: 7 December 2017 Accepted: 10 May 2018

Published online: 21 May 2018

\footnotetext{
References

1. Efthimiou P, Georgy S. Pathogenesis and management of adult-onset Still's disease. Semin Arthritis Rheum. 2006;36(3):144-52.

2. Gerfaud-Valentin $M$, Jamilloux Y, Iwaz J, Sève P. Adult-onset Still's disease. Autoimmun Rev. 2014;13(7):708-22.

3. Lenert A, Yao Q. Macrophage activation syndrome complicating adult onset Still's disease: a single center case series and comparison with literature. Semin Arthritis Rheum. 2016:45:711-6.

4. Maria AT, Le Quellec A, Jorgensen C, Touitou I, Rivière S, Guilpain P. Adult onset Still's disease (AOSD) in the era of biologic therapies: dichotomous view for cytokine and clinical expressions. Autoimmun Rev. 2014;11:1149-59.
} 
5. Kontzias A, Efthimiou P. The use of Canakinumab, a novel IL-1 $\beta$ long acting inhibitor, in refractory adult-onset Still's disease. Semin Arthritis Rheum. 2012;42(2):201-5.

6. Castañeda S, Blanco R, González-Gay MA. Adult-onset Still's disease: advances in the treatment. Best Pract Res Clin Rheumatol. 2016;30:222-38.

7. Pouchot J, Arlet JB. Biological treatment in adult-onset Still's disease. Best Pract Res Clin Rheumatol. 2012;26(4):477-87.

8. Suematsu R, Ohta A, Matsuura E, Takahashi H, Fujii T, Horiuchi T, Minota S, Ishigatsubo Y, Ota T, Takei S, Soejima S, Inoue H, Koarada S, Tada Y, Nagasawa K. Therapeutic response of patients with adult Still's disease to biologic agents: multicenter results in Japan. Modern Rheumatol. 2012;22:712-9.

9. Yamaguchi M, Ohta A, Tsunematsu T, Kasukawa R, Mizushima Y, Kashiwagi H, Kashiwazaki S, Tanimoto K, Matsumoto Y, Ota T. Preliminary criteria for classification of adult Still's disease. J Rheumatol. 1992;19:424-30.

10. Efthimiou P, Kontzias A, Ward CM, Ogden NS. Adult-onset Still's disease: can recent advances in our understanding of its pathogenesis lead to targeted therapy? Nat Clin Pract Rheumatol. 2007;3:328-35.

11. Rech J, Ronneberger M, Englbrecht M, Finzel S, Manger K, Manger B, Schett B. Successful treatment of adult-onset Still's disease refractory to TNF and IL-1 blockade by IL-6 receptor blockade. Ann Rheum Dis. 2010;70(2):390-2.

12. Mitamura M, Tada Y, Koarada S, Inoue H, Suematsu R, Ohta A, Nagasawa K. Cyclosporin A treatment for Japanese patients with severe adult-onset Still's disease. Modern Rheumatol. 2009;19:57-63.

13. Nakamura H, Odani T, Shimizu Y, Takeda T, Kikuchi H. Usefulness of tacrolimus for refractory adult-onset still's disease: report of six cases. Modern Rheumatol. 2016:26:963-7.
14. Murakami K, Fujii T, Yukawa N, Yoshifuji H, Kawabata D, Tanaka M, Usui T, Mimori T. Successful treatment of a patient with refractory adult Still's disease by tacrolimus. Modern Rheumatol. 2017;17:167-70.

15. Aksentijevich I, McDermott MF. Lessons from characterization and treatment of the autoinflammatory syndromes. Curr Opin Rheumatol. 2017;29:187-94.

16. Giampietro C, Ridene M, Lequerre T, Costedoat Chalumeau N, Amoura Z, Sellam J, Sibilia J, Bourgeois P, Fautrel B. Anakinra in adult-onset Still's disease: long-term treatment in patients resistant to conventional therapy. Arthritis Care Res. 2014;65:822-6.

17. Ryan JG, Masters SL, Booty MG, Habal N, Alexander JD, Barham BK, Remmers EF, Barron KS, Kastner DL, Aksentijevich I. Clinical features and functional significance of the P369S/R408Q variant in pyrin, the familial Mediterranean fever protein. Ann Rheum Dis. 2010;69(7):1383-8.

18. Ben-Chetrit E, Peleg H, Aamar S, Heyman SN. The spectrum of MEFV clinical presentations-is it familial Mediterranean fever only? Rheumatology. 2009:48(11):1455-9.

19. Slobodnick A, Shah B, Pillinger MH, Krasnokutsky S. Colchicine: old and new. Am J Med. 2015;128(5):461-70.

20. Leung YY, Yao Hui LL, Kraus VB. Colchicine-Update on mechanisms of action and therapeutic uses. Semin Arthritis Rheum. 2015;45(3):341-50.

21. Misawa T, Takahama M, Kozaki T, Kozaki T, Lee H, Zou J, Saitoh T, Akira S. Microtubule-driven spatial arrangement of mitochondria promotes activation of the NLRP3 inflammasome. Nat Immunol. 2013;14(5):454-60.
Ready to submit your research? Choose BMC and benefit from:

- fast, convenient online submission

- thorough peer review by experienced researchers in your field

- rapid publication on acceptance

- support for research data, including large and complex data types

- gold Open Access which fosters wider collaboration and increased citations

- maximum visibility for your research: over 100M website views per year

At BMC, research is always in progress.

Learn more biomedcentral.com/submissions 